\title{
Stasiun Interchange MRT Blok M Dengan Pendekatan Arsitektur BIOKLIMATIK DI JAKARTA
}

\author{
Naya Marsatyasti, Agung Kumoro W., Agus Heru Purnomo \\ Program Studi Arsitektur \\ Jurusan Arsitektur Fakultas Teknik \\ Universitas Sebelas Maret Surakarta \\ Email : naya.marsatyasti@gmail.com
}

\begin{abstract}
Everyday, more than four million commuters from DKI Jakarta's satellite regions commute to and from capital region. The tendency of Jabodetabek's expansion is so high that rising transportation cost significantly, decreasing level of mobility and quality of life. As shown in DKI Jakarta's SLHD (Status Lingkungan Hidup Daerah) in 2012, in order to support DKI Jakarta's transportation issues and decreasing impact of air pollution in Jakarta as a result of vehicles's usage, MRT is proclaimed to be one of transportation's solution. Aside from how to plan and design good MRT station both in terms of passengers needs of mobility, thermal requirement is also a design problem for building; associated with Jakarta located in tropical climate zone. Method or approach used is based on Bioclimatic Architecture focused on building thermal requirements obtained through bioclimatic chart analysis with manifestations of building mass arrangement to best orientation, percentage of openings and shadings to maximize natural lighting and ventilation, building material, landscape composition and building arrangement. The results obtained is Blok M MRT station design used as mass transportation systems's facilities based on Bioclimatic Architecture's principle.
\end{abstract}

Keywords: Architecture, Bioclimatic, Blok M, Mass Rapid Transit, Shading, Station.

\section{PENDAHULUAN}

Kerugian ekonomi akibat kemacetan lalu lintas di Jakarta ditaksir Rp 12,8 triliun / tahun yang meliputi nilai waktu, biaya bahan bakar dan biaya kesehatan. Sementara berdasarkan SITRAMP II tahun 2004 menunjukan bahwa bila sampai 2020 tidak ada perbaikan yang dilakukan pada sistem transportasi maka perkiraan kerugian ekonomi mencapai Rp 65 triliun/tahun. Saat ini, moda transportasi publik yang ada di Jakarta didominasi oleh kendaraan pribadi, dan hanya menyisakan 2\% saja bagi transportasi berbasis rel. Polusi udara akibat kendaraan bermotor memberi kontribusi $80 \%$ dari polusi di Jakarta. Dengan bertambahnya jumlah kendaraan yang tidak sebanding apabila dibandingkan dengan bertambahnya pembangunan jalan menyebabkan semakin menambah kemacetan di wilayah ibukota Jakarta. Faktanya suhu rata-rata permukaan Jakarta sudah pada taraf tidak nyaman yaitu $27^{\circ} \mathrm{C}$ dan akan bertambah menjadi $30^{\circ} \mathrm{C}$ pada tahun 2100, sedangkan suhu ideal pada bangunan di Jakarta adalah $26,4^{\circ} \mathrm{C}$.

Stasiun MRT sebagai manifestasi dari permasalahan transportasi ibukota direncanakan untuk dapat memenuhi tuntutan program ruang dan sirkulasi sebagai fasilitas utama dari stasiun MRT. Aspek struktur yang digunakan harus berfungsi sebagai pelindung terhadap kereta dan penumpang dari iklim tropis Jakarta dan kebutuhan peruangan stasiun. Selain itu bangunan stasiun dengan karakteristik stasiun layang membutuhkan struktur utama yang mengutamakan perkuatan dan kekokohan bangunan. Jaringan utilitas stasiun dijelaskan melalui diagram dari sumber utilitas yang digunakan sampai pendistribusiannya pada bangunan. Gubahan dan tata massa bangunan terbentuk dari pertimbangan prinsip arsitektur bioklimatik dan tidak mengganggu jalur lalu lintas yang berada di bawah bangunan. 


\section{METODE}

Metode yang digunakan dalam memperoleh rancangan Stasiun Interchange MRT Blok $M$ didasarkan pada penerapan prinsipprinsip Arsitektur Bioklimatik.

Konsep Arsitektur Bioklimatik dikemukakan pertama kali oleh Victor Olgyay pada tahun 1963. Bioklimatik terdiri dari dua kata, "Bio" yang berarti bentuk natural dari benda hidup dan "Climate" yang berarti pola reguler kondisi cuaca pada tempat tertentu. Bioklimatik merupakan interaksi antara bangunan dan lingkungan di mana dia berada, dengan tujuan memperbaiki kenyamanan termal dengan mengurangi pemanasan dan kebutuhan pendinginan bangunan.

Tujuan dari desain bioklimatik adalah untuk pemeliharaan kondisi kenyamanan termal di dalam bangunan. Faktor-faktor yang mempengaruhi kenyamanan termal adalah (Salmon, 1999) :

a. Daya tahan termal pakaian dan permukaan yang mengalami kontak langsung dengan tubuh,

b. Temperatur udara dan permukaan lingkungan,

c. Kecepatan angin,

d. Tekanan uap air.

\subsection{Prinsip Arsitektur Bioklimatik}

Pendekatan bioklimatik pada desain arsitektur bertitik tolak dari dua hal fundamental untuk menentukan strategi desain yang responsif terhadap lingkungan yaitu kenyamanan manusia dengan kontrol iklim dan penggunaan energi secara pasif. Beberapa prinsip yang harus diperhatikan ketika mendesain dengan pendekatan bioklimatik adalah :

a. Memanfaatkan radiasi matahari secara efisien dan mendukung material yang ramah lingkungan,

b. Menggabungkan sistem aktif dan pasif untuk menghasilkan solusi integratif dalam mencapai kontrol iklim,

c. Melakukan pendekatan pada aspek eksterior dan interior bangunan; mengintegrasikan lansekap, material konstruksi, dan iklim mikro bangunan dengan lingkungan.

\subsection{Penerapan dan Kriteria Arsitektur Bioklimatik}

Beberapa faktor yang harus diperhatikan ketika mendesain dengan pendekatan iklim adalah (Koch-Nielsen, 2007) :

a. Untuk kawasan hangat dan lembab, pergerakan udara sangat dibutuhkan,

b. Orientasi bangunan dan jalan diarahkan untuk menangkap hembusan angin,

c. Gabungan dari ketinggian bangunan mendukung ventilasi dan menggunakan salah satu bagian dari bangunan sebagai shading,

d. Vegetasi yang ada tidak boleh menghalangi pergerakan udara,

e. Permukaan yang berpori dibutuhkan untuk mengurangi tampias angin dan air hujan ketika curah hujan sedang tinggi.

Berdasarkan teori yang telah disebutkan, poin-poin penerapan bioklimatik pada bangunan adalah :

a. Orientasi dalam dan luar bangunan,

b. Perangkat sunshading, bagaimana strategi penggunaan perangkat penghalang matahari yang sesuai dengan kondisi iklim setempat;

c. Ventilasi bangunan, bagaimana strategi akan ventilasi yang baik untuk pencahayaan alami dan pendinginan bangunan;

d. Material bangunan, strategi penggunaan material dengan daya penyimpanan panas yang sesuai dengan iklim setempat;

e. Lansekap, memberikan strategi tata lansekap untuk mengalirkan pergerakan udara yan baik di luar dan dalam bangunan;

f. Desain pasif, sumber energi yang berlimpah dapat digunakan menjadi sumber energi lain seperti penggunaan pencahayaan alami sebagai penerangan pada siang hari.

\section{ANALISIS}

\subsection{Analisis Eksisting Tapak}

Tapak yang digunakan adalah tapak yang sudah ditentukan PT. MRT Jakarta. Tapak stasiun MRT Blok M berada di Jalan Panglima Polim Raya, Jakarta Selatan 12130. Tapak ini berada tepat di atas jalan Panglima Polim Raya dengan luas tapak $\pm 6.300 \mathrm{~m}^{2}$. 
Batas-batas tapak :

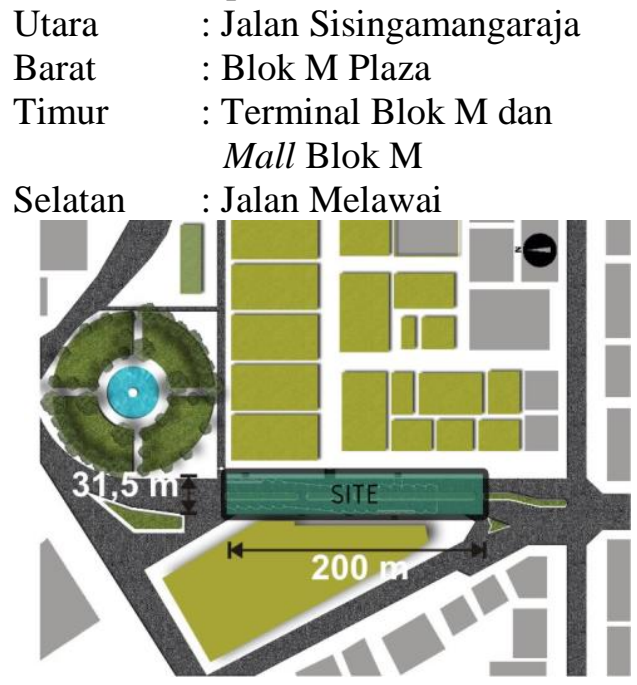

Gambar 1. Lokasi Tapak Stasiun MRT

\subsection{Analisis Klimatologis Pada Tapak}

\subsubsection{Analisis Matahari dan Suhu Udara}

Berdasarkan data Analisis

Musim Hujan 2013/2014 dan

Prakiraan Musim Kemarau 2014

Provinsi DKI Jakarta bersumber Badan Meterologi, Klimatologi dan Geofisika Stasiun Klimatologi Pondok Betung Tangerang; suhu udara maksimum absolut mencapai $35,4^{\circ} \mathrm{C}$ dan suhu minimum absolut sebesar $22,4^{\circ} \mathrm{C}$ terjadi pada bulan Agustus 2013. Dengan suhu udara ideal adalah kurang lebih $26,4^{\circ} \mathrm{C}$.

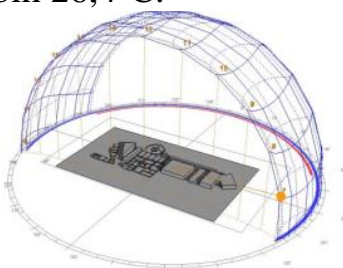

Gambar 2. Analisis Matahari Pada

Tapak Pukul 07.00 WIB

Sumber : Ecotect Analysis 2011

Berdasarkan analisis matahari pada tapak stasiun MRT, perlu ada perhatian khusus untuk pemasukkan pencahayaan alami pada pagi hari pada bagian koridor penghubung menuju stasiun dan elemen sirkulasi vertikal yang menjadi pintu masuk stasiun pada bagian barat stasiun untuk penerangan ketika sore dan malam hari. Pertimbangan perletakaan bukaan dimaksimalkan pada bagian timur, utara dan selatan; sedangkan pada bagian barat pemakaian shading wall sangat diperlukan (Gambar 2).

\subsubsection{Analisis Angin}

Arah angin di bagian Jakarta Selatan dipengaruhi angin Muson Barat terutama pada bulan MeiOktober. Angin Muson Barat bersifat basah dan lembab. Berikut analisis kecepatan angin pada tapak stasiun Interchange MRT Blok M Jakarta :

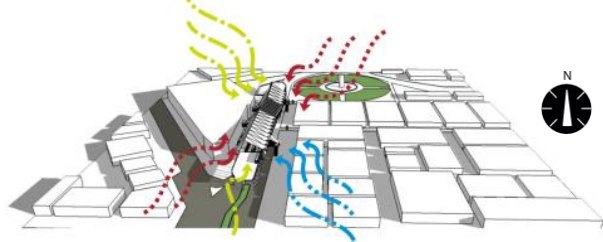

Gambar 3. Analisis Kecepatan Angin

Batas kecepatan angin yang ideal berada pada angka $1.5 \mathrm{mps}$ atau 3 knot dengan karakteristik berangin. Berdasarkan data kecepatan angin di Jakarta angin dengan kecepatan paling tinggi yaitu 7-11 knot berhembus dari arah barat daya dan timur laut (Gambar 3, panah warna merah). Sedangkan pada arah selatan dan barat laut angin yang berhembus cukup nyaman berada pada angka 1-4 knot (Gambar 3, panah warna hijau). Pada arah tenggara berhembus angin dengan kecepatan paling rendah 0-4 knot (Gambar 3, panah warna biru).

\subsubsection{Analisis Kelembapan}

Rata-rata kelembapan di Jakarta adalah $60 \%$ yang berarti sudah cukup nyaman, namun dapat meningkat atau menurun sesuai musim sepanjang tahun. Untuk itu perlu ada strategi dalam menyiasati kondisi termal bangunan agar tetap dalam kondisi nyaman. Untuk kawasan dengan kondisi iklim lembab hangat; ventilasi natural dapat digunakan. 


\subsubsection{Tabel Bioklimatik}

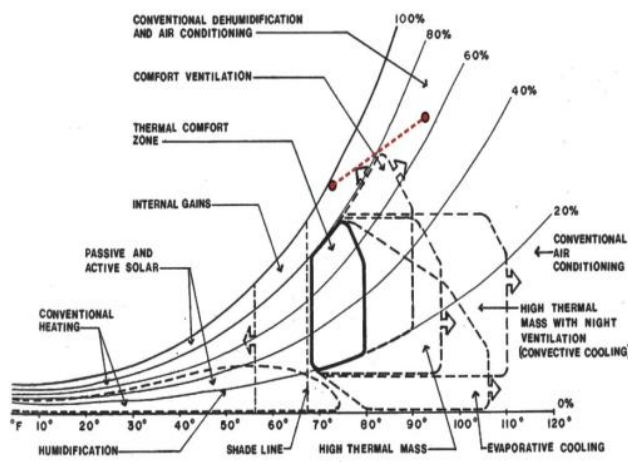

Gambar 4. Tabel Bioklimatik

Data Iklim Jakarta kemudian dianalisis pada tabel bioklimatik untuk mendapatkan strategi desain bioklimatik yang sesuai. Berdasarkan tabel bioklimatik, strategi desain yang dapat diterapkan adalah ventilasi alamiah, dehumidifikasi konvensional dan penyejuk udara, dan shading.

\subsubsection{Analisis Peruangan}

Analisis ini dilakukan dengan mengelompokkan kebutuhan ruang berdasarkan kelompok kegiatan, rincian kegiatan dan pelaku pada Stasiun Interchange MRT Blok M di Jakarta.

Tabel 1. Kebutuhan Ruang

\begin{tabular}{|c|c|c|}
\hline $\begin{array}{l}\text { Pelaku } \\
\text { Kegiatan }\end{array}$ & Kegiatan & $\begin{array}{l}\text { Kebutuhan } \\
\text { Ruang }\end{array}$ \\
\hline \multirow{8}{*}{ Penumpang } & \multirow{3}{*}{$\begin{array}{l}\text { Masuk/keluar } \\
\text { stasiun }\end{array}$} & $\begin{array}{l}\text { Pintu masuk } \\
\text { stasiun }\end{array}$ \\
\hline & & $\begin{array}{l}\text { Free } \\
\text { concourse }\end{array}$ \\
\hline & & $\begin{array}{l}\text { Koridor } \\
\text { Penghubung }\end{array}$ \\
\hline & \multirow[b]{2}{*}{$\begin{array}{l}\text { Membeli } \\
\text { tiket }\end{array}$} & $\begin{array}{l}\text { Area mesin } \\
\text { tiket otomatis }\end{array}$ \\
\hline & & $\begin{array}{l}\text { Loket } \\
\text { pembelian } \\
\text { tiket } \\
\text { langganan }\end{array}$ \\
\hline & \multirow{3}{*}{$\begin{array}{l}\text { Menuju paid } \\
\text { area }\end{array}$} & $\begin{array}{l}\text { Gerbang tiket } \\
\text { otomatis }\end{array}$ \\
\hline & & $\begin{array}{l}\text { Paid } \\
\text { concourse }\end{array}$ \\
\hline & & $\begin{array}{l}\text { Sirkulasi } \\
\text { vertikal dan } \\
\text { ruang }\end{array}$ \\
\hline
\end{tabular}

\begin{tabular}{|c|c|c|}
\hline & & $\begin{array}{l}\text { sirkulasi } \\
\text { horizontal }\end{array}$ \\
\hline & $\begin{array}{l}\text { Kegiatan } \\
\text { komersil }\end{array}$ & $\begin{array}{l}\text { Area } \\
\text { Pertokoan }\end{array}$ \\
\hline & $\begin{array}{l}\text { Menunggu } \\
\text { MRT }\end{array}$ & \multirow{2}{*}{ Peron } \\
\hline & $\begin{array}{l}\text { Naik/turun } \\
\text { MRT }\end{array}$ & \\
\hline $\begin{array}{l}\text { Kereta } \\
\text { MRT }\end{array}$ & $\begin{array}{l}\text { Berhenti } \\
\text { kereta }\end{array}$ & Rel kereta \\
\hline \multirow{8}{*}{$\begin{array}{l}\text { Penumpang, } \\
\text { Pengelola, } \\
\text { Staff Servis, } \\
\text { Staff } \\
\text { Pengelola } \\
\text { Retail }\end{array}$} & Metabolisme & Toilet \\
\hline & Ibadah & Mushola \\
\hline & $\begin{array}{l}\text { Kegiatan ibu } \\
\text { dan anak }\end{array}$ & $\begin{array}{l}\text { Ruang ibu dan } \\
\text { anak }\end{array}$ \\
\hline & \multirow{3}{*}{$\begin{array}{l}\text { Pergerakan } \\
\text { dalam stasiun }\end{array}$} & Elevator \\
\hline & & Eskalator \\
\hline & & Tangga \\
\hline & $\begin{array}{l}\text { Fasilitas } \\
\text { Keselamatan }\end{array}$ & $\begin{array}{l}\text { Tangga } \\
\text { darurat }\end{array}$ \\
\hline & $\begin{array}{l}\text { Mengambil } \\
\text { uang }\end{array}$ & Ruang ATM \\
\hline
\end{tabular}

\subsubsection{Analisis Pencapaian}

Akses menuju stasiun akan berada pada beberapa pedestrian dan sebuah koridor yang menghubungkan stasiun dengan plaza Blok M pada sisi kiri tapak. Area drop off juga diberikan pada barat dan timur tapak untuk mengakomodasi penumpang drop off. Kriteria perletakkan akses masuk stasiun adalah (Griffin, 2004) :

a. Harus jelas terlihat dari luar stasiun dan dapat dengan mudah ditemukan di antara objek urban di lingkungan sekitarnya.

b. Diletakkan aksesibel dari penyebrangan, plaza publik, dan fasilitas pedestrian lainnya

c. Diletakkan pada area yang menyediakan kemudahan akses menuju moda transportasi lain

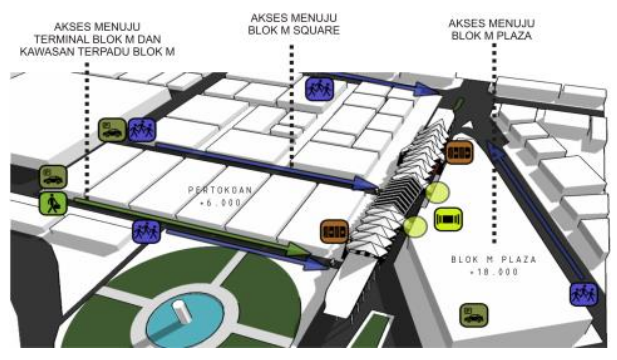

Gambar 4. Analisis Pencapaian 
Berdasarkan kriteria perletakkan akses masuk dan analisis pencapaian penumpang yang berada pada sekitar tapak, berikut adalah ilustrasi akses masuk Stasiun Interchange MRT Blok M :

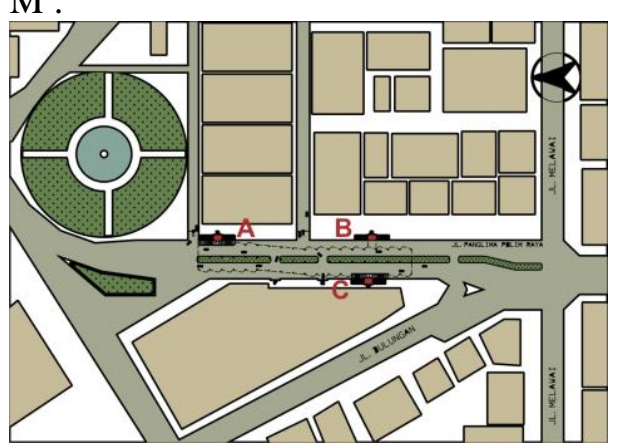

Gambar 5. Perletakkan Pintu Masuk Stasiun

\subsubsection{Analisis Pemintakatan Bangunan}

Analisis ini ditentukan berdasarkan pola hubungan ruang secara umum yang kemudian dikelompokkan berdasarkan area publik, area semi publik, area privat dan area servis.

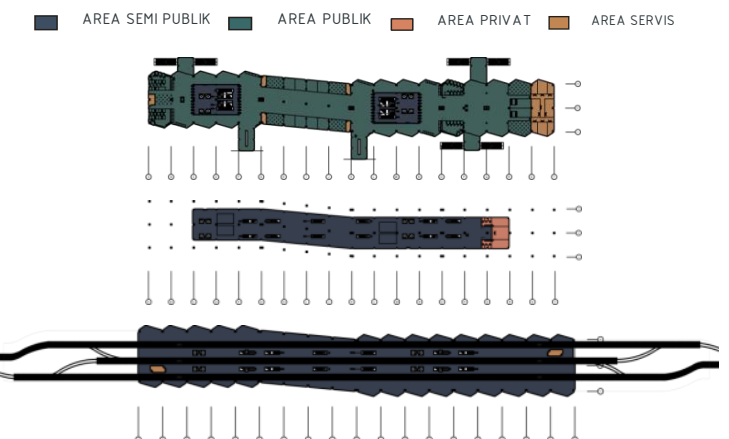

Gambar 6. Analisis Pemintakatan

\subsubsection{Analisis Orientasi Bangunan}

Bentuk tapak yang memanjang dan bangunan di sekitar tapak yang padat tidak memungkinkan bangunan berorientasi utara-selatan, maka dari itu bentuk orientasi yang menangkap sinar matahari dibentuk dari modul-modul kecil berorientasi utara-selatan yang kemudian disusun memanjang mengikuti bentuk tapak. Modular kecil adalah peruangan pada bangunan stasiun yang diatur dan dibagi sehingga setiap ruangan akan memiliki orientasi utara-selatan dan tidak terkenal silau berlebihan dari sinar matahari (Gambar 7).

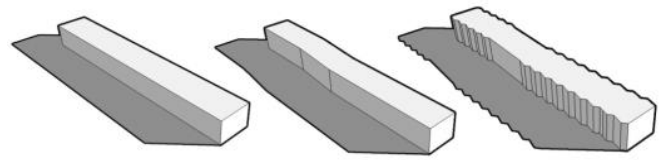

Gambar 7. Analisis Orientasi Bangunan

Tujuan pembentukan modular dengan orientasi saling berkebalikan adalah untuk menyeimbangkan pemasukan aliran angin, ventilasi silang dan penghalau sinar matahari berlebih.

\subsubsection{Analisis}

\section{Ventilasi/Bukaan}

\section{Bangunan}

Pembukaan untuk ventilasi, cahaya, dan perolehan matahari dapat dipisahkan atau digabungkan. Untuk stasiun MRT Blok M fungsi bukaan digabung menjadi satu untuk efisiensi komponen bangunan. Kecepatan ratarata berkisar dari $32 \%-65 \%$ dari kecepatan pada eksterior bangunan jika posisi bukaan berada pada satu dinding yang sama dan terdapat lebih dari dua bukaan (Brown, 1990).

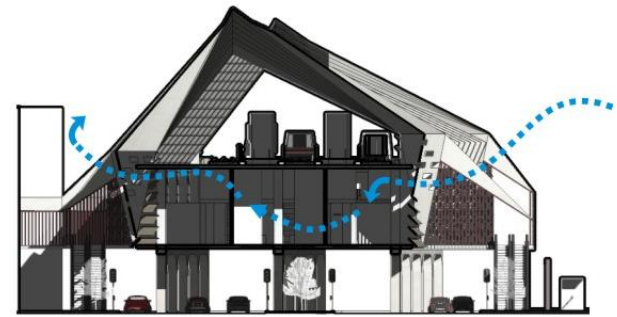

Gambar 8. Analisis Ventilasi Bangunan

Bukaan untuk pemasukkan penghawaan alami diarahkan pada bagian barat laut dan tenggara untuk pemasukkan angin bersifat tidak panas dengan kecepatan 4-7 knot agar kecepatan angin rata-rata pada interior menjadi 1,15-1,3 $\mathrm{m} / \mathrm{s}$ karakteristik berangin yang berasal dari barat laut, utara dan selatan sedangkan tenggara memberi kecepatan rata-rata interior menjadi $0,3-0,65 \mathrm{~m} / \mathrm{s}$ karakteristik sepoi-sepoi (Gambar 8). 


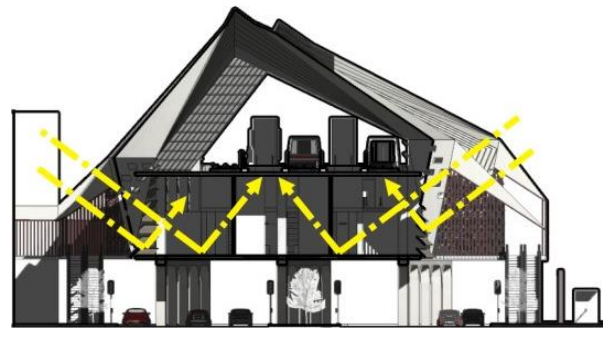

Gambar 9. Analisis Ventilasi Bangunan

Kotak persegi panjang dengan besaran $1,5 \mathrm{~m} \quad \mathrm{x} \quad 0,5 \mathrm{~m}$ menjadi dimensi dari bukaan pada selubung bangunan untuk mencapai karakteristik bukaan kecil namun tetap memasukkan cahaya dengan menambah jumlah bukaan pada dinding dengan acuan minimal bukaan $5 \%$ dan maksimal $20 \%$ pada satu luasan dinding (Brown, 1990). Pada stasiun MRT Blok M didapatkan pada bagian barat laut dan tenggara besar bukaan $7,5 \%$ dan pada bagian utara dan selatan sebesar $9,6 \%$ pada satu luasan dinding.

\subsubsection{Analisis Shading Bangunan}

Shading pada bangunan stasiun difokuskan pada bagian timur dan barat bangunan stasiun. Shading yang digunakan memiliki karakteristik peneduhan yang sama tetapi masih memantulkan cahaya ke dalam ruangan.

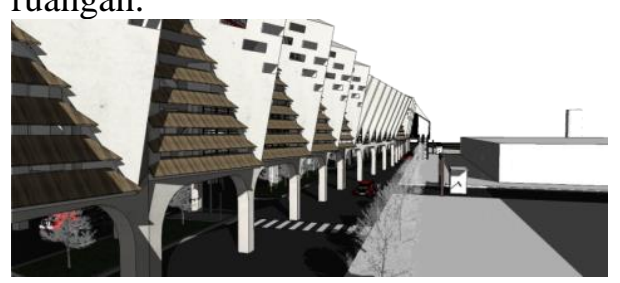

Gambar 10. Aplikasi Shading Pada

Shading yang digunakan berupa kombinasi dari kisi vertikal dan horisontal dengan kemiringan $45^{\circ}$ terhadap kulit bangunan. Kisi dengan bentuk ini memiliki karakteristik pengurangan iluminasi 50\% (Brown, 1990). Kisi-kisi shading memungkinkan menjaga karakteristik peneduhan yang sama tetapi masih memantulkan cahaya ke dalam ruang (Gambar 10).

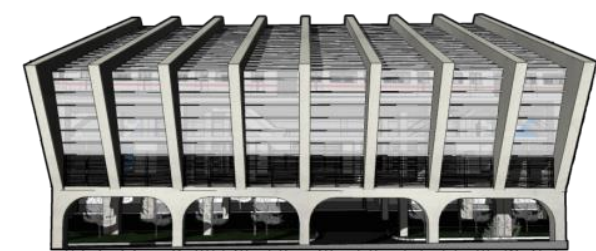

Gambar 11. Aplikasi Perforated Screen Pada Fasade Bangunan

Shading juga digunakan sebagai lapisan luar dari laminated glass pada ruang transisi. Alat peneduh dapat beraneka ragam ukuran tanpa mengubah karakteristik peneduhan, sepanjang rasio kedalaman dan jarak elemen tetap konstan (Gambar 11).

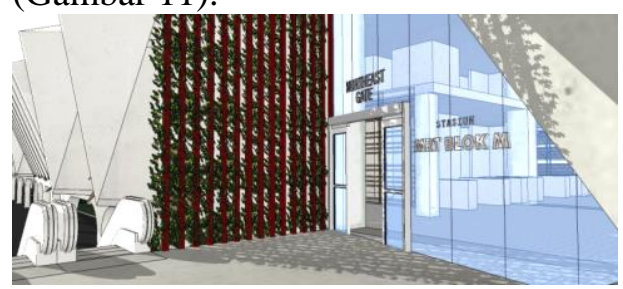

Gambar 12. Aplikasi Shading Pada Pintu Masuk Bangunan

Pada area pintu masuk dan koridor penghubung diberi dinding shading sebagai selubungnya untuk menghindari terbentuknya ruang tertutup yang tidak dapat mengalirkan pergerakan udara. Shading yang digunakan berupa kisi-kisi vertikal yang dikombinasikan dengan tanaman rambat sebagai pendinginan evaporatif (Gambar 12).

\subsubsection{Analisis Material Bangunan}

Material yang digunakan memiliki kriteria yang disesuaikan dengan kebutuhan iklim tropis adalah sebagai berikut (Koch-Nielsen, 2007) :

a. Material dengan daya penyimpanan panas rendah dan ringan,

b. Permukaan atap yang reflektif untuk mereduksi panas ke dalam bangunan,

c. Material dengan insulasi termal pada atap dan dinding,

d. Menghindari pemakaian material alumunium, besi metal, kayu, nonlaminated glass. 
Berikut adalah pemakaian material dikelompokkan berdasarkan lantai, dinding, dan plafon/atap stasiun :

Tabel 2. Material Bangunan

\begin{tabular}{|l|l|l|}
\hline \multicolumn{1}{|c|}{ Lantai } & \multicolumn{1}{|c|}{ Dinding } & Plafon/Atap \\
\hline Granit & Stainless Steel & $\begin{array}{l}\text { Stainless } \\
\text { Steel }\end{array}$ \\
\hline Ubin Teraso & Beton & Baja \\
\hline \multirow{5}{*}{} & $\begin{array}{l}\text { Porcelain } \\
\text { Enamel }\end{array}$ & $\begin{array}{l}\text { Porcelain } \\
\text { Enamel }\end{array}$ \\
\cline { 2 - 3 } & $\begin{array}{l}\text { Laminated } \\
\text { Glass }\end{array}$ & $\begin{array}{l}\text { Beton Tipis } \\
\pm 6 \mathrm{~cm}\end{array}$ \\
\cline { 2 - 3 } & $\begin{array}{l}\text { Grass Fibre } \\
\text { Board }\end{array}$ & \\
\cline { 2 - 3 } & Plywood & \\
& \multicolumn{2}{|l}{} \\
\end{tabular}

\subsubsection{Analisis Lansekap Bangunan}

Lansekap bangunan difungsikan sebagai penyaring udara dan penyeimbang suhu udara antar dalam ruangan dan luar ruangan. Lansekap diletakkan pada sisi-sisi di pintu masuk stasiun berupa tanaman rambat yang dikombinasikan dengan shading bangunan dan sebagai pendinginan evaporatif bangunan (Gambar 12).

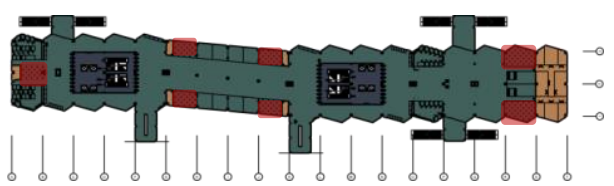

Gambar 13. Aplikasi Lansekap Pada Interior

Lansekap juga diberikan pada bagian dalam bangunan tepatnya pada area free concourse sebagai penyaring udara dan pendinginan ruang di sekitarnya (Gambar 14, kotak warna merah).

\subsubsection{Analisis Passive Design Bangunan}

Prinsip dari passive design adalah (Salmon, 1999) :

a. Didesain untuk menerima atau menolak panas matahari ketika dibutuhkan,

b. Mempunyai integritas termal untuk menjaga kenyamanan pada iklim ekstrim,

c. Menggabungkan kemampuan memelihara kehadiran dan ketidakhadiran panas di dalam bangunan.

Desain pasif menitikberatkan pada penghematan energi, dalam kasus ini dapat dianalisis melalui penggunaan energi tambahan oleh bangunan seperti pencahayaan dan penghawaan buatan. Penghawaan dan pencahayaan yang digunakan diletakkan pada titik yang paling dibutuhkan dan tidak disemua tempat pada bangunan.

\subsubsection{Analisis Gubahan dan Tata Massa}

Kriteria dari gubahan dan tata massa stasiun MRT Blok M adalah :

a. Pertimbangan efisiensi ruang,

b. Gubahan dengan fleksibilitas terhadap sirkulasi dan tapak.

Gubahan dan tata massa Stasiun Interchange MRT Blok M merupakan hasil dari penerapan bioklimatik berdasarkan analisis orientasi dan analisis ventilasi/bukaan bangunan dan kebutuhan efisiensi peruangan. Berdasarkan posisi dan bentuk tapak yang berbentuk kotak memanjang menyesuaikan rel kereta MRT, bentuk dan gubahan massa yang sesuai adalah bentuk kotak sebagai massa tunggal dengan pengembangan bentuk linier mengikuti sumbu rel kereta MRT.

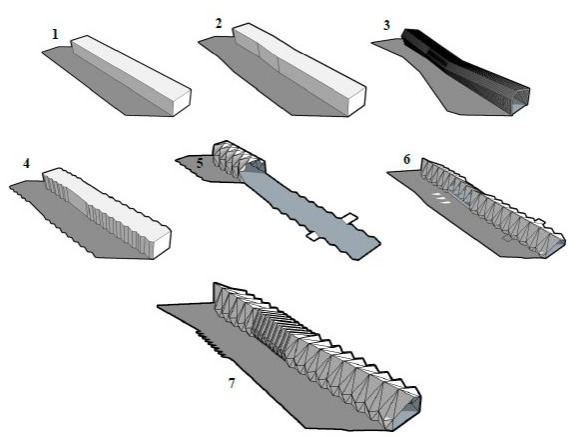

Gambar 14. Analisis Gubahan dan Tata Massa

Massa kotak tunggal (1) dipotong dan kemudian diberi patahan arah pada bagian tengah untuk dijadikan area transisi yang berfungsi sebagai atrium environment (2). Kemudian massa diberi selubung yang berfungsi sebagai shading bangunan 
(3) namun perletakkan bukaan menjadi minimal dan terkesan monoton dengan bentuk linier massa. Analisis orientasi menghasilkan bentuk bangunan yang terbentuk dari modular ruang yang berupa gabungan dari modular yang berorientasi untuk menangkap angin karakteristik sejuk berkecepatan sedang dan modular dengan orientasi sebaliknya untuk menyeimbangkan aliran angin yang masuk (4). Kemudian penutup atap diberikan untuk sekaligus menjadi selubung bangunan, namun dengan bentuk atap ini akan terbentuk banyak lipatan yang cenderung menampung air hujan dan dapat menyebabkan ruang di dalamnya menjadi lembab (5). Bentuk atap dikembangkan menjadi bentuk atap segitiga dengan struktur folded plate yang diberi kemiringan berbeda agar bagian timur mendapat cahaya maksimal dan kebalikannya pada bagian barat (6). Kemudian bentuk dikembangkan lagi menjadi atap folded plate yang digabungkan dengan selubung bangunan dengan bentuk serupa yang kemudian diberi perletakkan shading dan ventilasi; ruang transisi sebagai penghubung kuat dengan eksterior bangunan dan digunakan sebagai area pertokoan di mana pengunjung menetap dalam waktu lama diberi penutup atap berupa laminated glass yang dikombinasikan dengan beam dan shading (7).

\subsubsection{Analisis Tampilan Bangunan}

Bukaan dan shading menjadi fitur dominan pada bangunan. Material kaca ditemukan pada bagian tengah stasiun, difungsikan sebagai penutup atrium environment yang memiliki hubungan kuat dengan eksterior bangunan. Bangunan stasiun cenderung masif dengan perlubangan dan bentuk shading pada selubung bangunannya untuk menjaga keseimbangan pemasukan maupun pengeluaran pencahayaan dan penghawaan alami ke dalam bangunan.

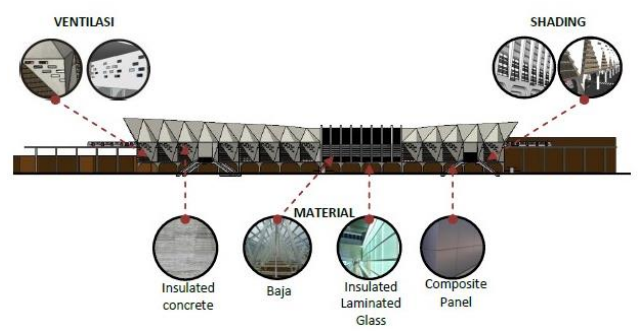

Gambar 15. Analisis Tampilan Warna pada tampilan bangunan didominasi warna abu terang agar tidak menyebabkan silau bagi lingkungannya dan menjaga penyerapan panas bangunan tidak terlalu banyak. Material yang digunakan pada bagian luar bangunan adalah insulated laminated glass untuk kaca, composite panel untuk pelapis shading, baja dan beton yang diinsulasi untuk perkuatan dan daya penyerapan panas rendah agar kenyamanan termal dalam bangunan tetap terjaga.

\subsubsection{Analisis Struktur Bangunan}

\section{a. Upper Structure}

Kriteria atap berdasarkan iklim tropis :

1) Memberi perlindungan radiasi sinar matahari,

2) Pergerakan udara melewati permukaan untuk pendinginan bangunan,

3) Perlindungan dari hujan. Atap bangunan Stasiun MRT Blok M membutuhkan atap dengan bentang lebar agar tidak membutuhkan banyak kolom yang mengganggu area peron yang berada langsung di bawah atap. Struktur atap yang kemudian digunakan adalah folded plate berdasarkan analisis gubahan dan tata massa.

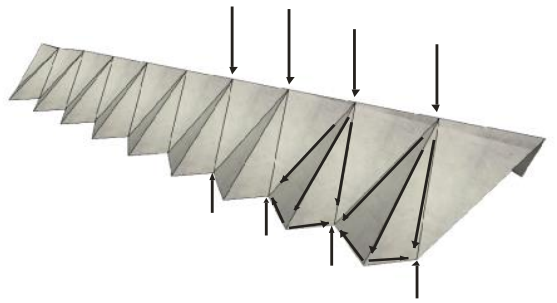

Gambar 16. Gaya Pada Atap Folded Plate 
Struktur atap folded plate ini digunakan pada sebagian besar massa bangunan stasiun, sedangkan pada bagian atrium environment menggunakan konstruksi baja ringan dikombinasikan dengan laminated glass.

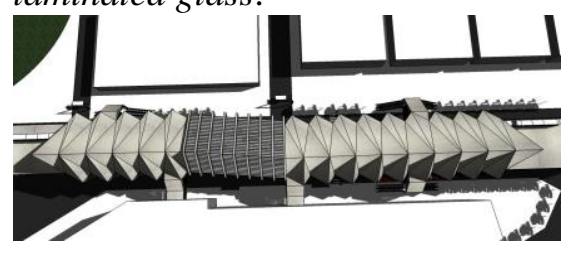

Gambar 17. Atap Stasiun

b. Super Structure

Kriteria super structure bangunan stasiun adalah :

1) Kekokohan bangunan,

2) Menahan beban pergerakan penumpang dan kereta.

Berdasarkan pertimbangan kekokohan dan stabilitas bangunan, super structure yang digunakan adalah struktur rangka (rigid frame).

Berdasarkan kebutuhan peruangan stasiun MRT Blok M, struktur transfer beam diberlakukan pada balok yang menyangga kolom pada atrium environment dan balok yang menyangga kolom lantai mezzanine. Transfer beam adalah balok pemikul yang menyalurkan beban di atasnya pada titik tumpuan yang lebih sedikit (konsentrasi beban pada beberapa tumpuan).
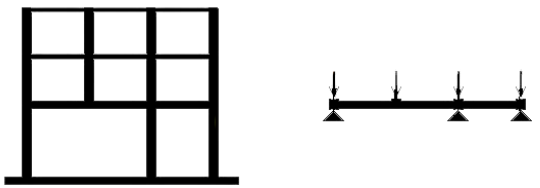

Gambar 18. Gaya Pada Transfer Beam

\section{c. Sub Structure}

Kriteria sub structure stasiun MRT Blok M adalah :

1) Efisiensi konstruksi struktur,

2) Pondasi kokoh untuk menahan bangunan dengan konstruksi bangunan layang.
Berdasarkan kriteria yang ada tiang pancang digunakan sebagai sub structure dengan didukung struktur dilatasi dengan dua kolom karena bangunan stasiun yang memiliki bentuk linier sepanjang $180 \mathrm{~m}$.

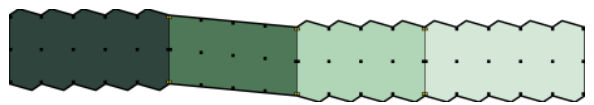

Gambar 19. Pembagian Dilatasi

\section{KESIMPULAN (KONSEP DESAIN)}

Stasiun Interchange MRT Blok M memiliki daya tampung penumpang sebesar 1478 pada saat peak hour. Stasiun ini memiliki konfigurasi peron gabungan dari center platform dan side platform untuk memudahkan pencapaian menuju 3 jalur kereta MRT. Elemen sirkulasi vertikal utama adalah eskalator menuju lantai stasiun yang berada 6 $\mathrm{m}$ di atas permukaan tanah. Elemen sirkulasi vertikal yang digunakan pada interior bangunan adalah tangga, eskalator dan elevator yang diletakkan pada paid concourse.

Konsep perancangan Stasiun Interchange MRT Blok $\mathrm{M}$ merupakan manifestasi dari penerapan prinsip-prinsip Arsitektur Bioklimatik sebagai respon dari iklim tropis pada lokasi stasiun. Strategi utama dari bioklimatik terlebih dahulu ditentukan melalui tabel bioklimatik yang dikemukakan oleh Olgyay.

Orientasi optimal bangunan yang tidak memungkinkan diberi respon pembagian massa bangunan menjadi bentuk modular ruang dengan orientasi optimal. Penggunaan bentuk dan ukuran ventilasi/bukaan didasarkan pada kebutuhan termal bangunan. Penghawaan buatan menggunakan radiant cooling dan menghindari penggunaan AC (Air Conditioning). Penggunaan bentuk dan perletakkan shading didasarkan pada analisis matahari dan angin bangunan untuk menyeimbangkan pemasukan dan pengeluaran cahaya maupun penghawaan alami. Material yang digunakan didasarkan pada karakteristik dengan penyimpanan panas dan ringan agar tidak menambah beban struktur bangunan. Lansekap bangunan berfungsi sebagai pendingin ruang dalam bangunan dan penyaring udara dengan penerapan pendinginan evaporatif. Gubahan dan tata 
massa bangunan merupakan hasil penerapan dari analisis bioklimatik pada bangunan (Gambar 15). Tampilan bangunan didominasi oleh shading, ventilasi dan bentuk atap yang disesuaikan dengan kebutuhan bangunan pada iklim tropis (Gambar 21). Struktur dan utilitas bangunan disesuaikan dengan kebutuhan peruangan stasiun.

Berikut adalah gambar hasil rancangan dari Stasiun Interchange MRT Blok M dengan pendekatan Arsitektur Bioklimatik di Jakarta yang menunjukkan potongan bangunan (Gambar 20), interior pada lantai mezzanine yang difungsikan sebagai area sirkulasi (Gambar 22), dan interior peron stasiun (Gambar 23) :

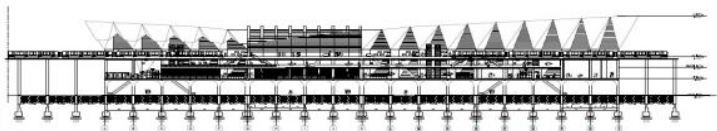

Gambar 20. Potongan Stasiun MRT Blok M

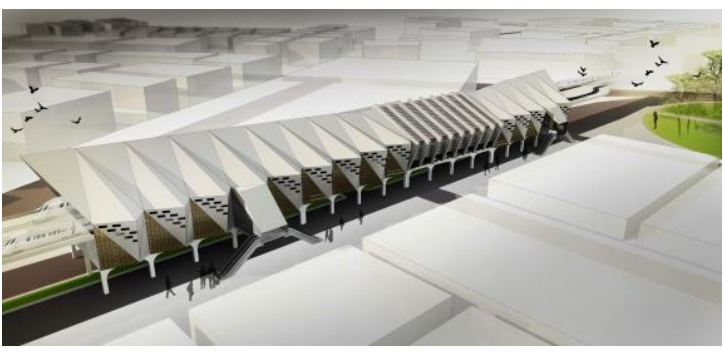

Gambar 21. Perspektif Eksterior

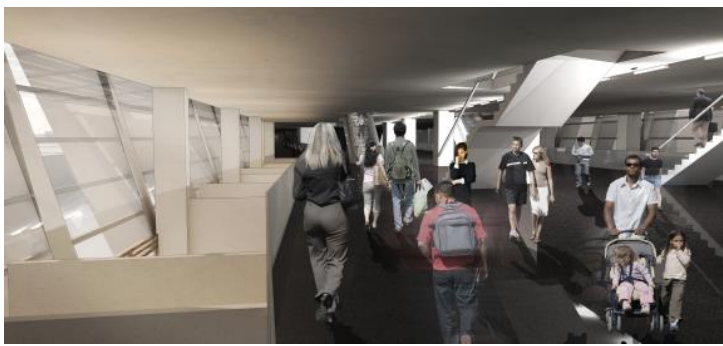

Gambar 22. Interior Lantai Mezzanine

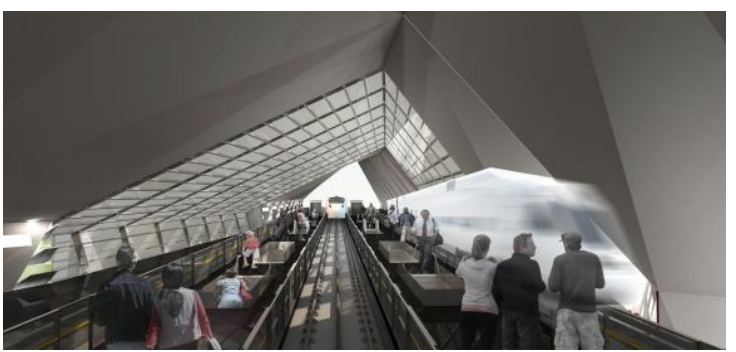

Gambar 23. Interior Peron Stasiun

\section{REFERENSI}

Badan Meteorologi Klimatologi dan Geofisika Stasiun Klimatologi Klas II Pondok Betung. 2014. Analisis Musim Hujan 2013/2014 dan Prakiraan Musim Kemarau 2014.

Brown, G.Z. 1990. Matahari, Angin, dan Cahaya. Intermatra : Bandung.

Koch-Nielsen, Holger. 2007. Stay Cool : A Design Guide For The Built Environment In Hot Climates. Earthscan : New York.

Salmon, Cleveland. 1999. Architectural Design For Tropical Regions. John Wiley \& Sons, Inc : Canada.

W. Griffin, Kenneth. 2004. Building Type Basics For Transit Facilities. John Wiley \& Sons, Inc. : New Jersey.

WWw.jakartamrt.com

www.hubdat.dephub.go.id/data-ainformasi/pdda/tahun-2012 